Research Paper:

\title{
Post-operative Morbidity and Mortality of Lumbar Spinal Stenosis at a Teaching Hospital in North-Eastern Benin
}

Holden Olatoundji Fatigba ${ }^{1}$ (D) Luphin Hode ${ }^{2}$ (D), Kisito Quenum ${ }^{1}$ (D), Thierry Alihonou ${ }^{2}$ (D, Kofi-Mensa Savi de Tove ${ }^{3}$ (D) Alexandre S. Allodé $^{4}$ (D)

1. Department of Neurosurgery, Medicine School of Parakou University, Borgou, Benin, Africa

2. Department of Trauma and Orthopedic Surgery, Medicine School of Abomey-Calavi University, Benin, Africa

3. Department of Radiodiagnosis and Medical Imaging, Medicine School of Parakou University, Borgou, Benin, Africa

4. Department General Surgery, Medicine School of Parakou University, Borgou, Benin, Africa

\begin{tabular}{|l|l|l}
$\begin{array}{l}\text { Use your device to scan } \\
\text { and read the article online }\end{array}$ & $\begin{array}{l}\text { Crtation: Olatoundji Fatigba H, Hode L, Quenum K, Alihonou T, Savi de Tove KM, Allodé AS. Post-operative Morbidity and } \\
\text { Mortality of Lumbar Spinal Stenosis at a Teaching Hospital in North-eastern Benin. Iran J Neurosurg. 2020; 6(1):13-20. http:// } \\
\text { dx.doi.org/10.32598/irjns.6.1.3 }\end{array}$ \\
doi: $:$ http://dx.doi.org/10.32598/irjns.6.1.3
\end{tabular}

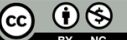

Article info:

Received: 07 Jul 2019

Accepted: 02 Dec 2019

Available Online: 01 Jan 2020

Keywords:

Spinal stenosis, Laminectomy, Post-operative morbidities, Dura mater, Wound infection

\section{A B STRACT}

Background and Aim: Surgical management of Lumbar Spinal Stenosis (LSS) is a common practice. This study aimed to report the morbidities and mortalities observed during surgical treatment of LSS and the outcome of these patients after management over an 8-year study period.

Methods and Materials/Patients: It was a retrospective, descriptive, and transversal study performed at the Departmental Teaching Hospital of Borgou in the Republic of Benin (West Africa) from January 2010 to December 2018. This study included the patients who underwent surgical management for LSS. Type of complication, its management, and the patient's outcome was registered.

Results: During the study period and based on the selection criteria, 239 patients were selected. These patients were divided into 135 men (56.5\%) and 104 women (43.5\%). The mean age of the patients was $52.3 \pm 10.9$ years. Laminectomy was performed on one, two, and three lumbar spinal segments in $17.6 \%, 55.6 \%$ and $26.8 \%$ of cases, respectively. Laminectomy was associated with discectomy in $6.3 \%$ of the cases. No arthrodesis with spinal fixation was performed. Ninetypercent of patients had no post-operative complications. Functional postoperative results were considered excellent, good, acceptable and poor in $32.1 \%, 52.1 \%$, $10.9 \%$ and $4.9 \%$ of cases, respectively. Five types of complications were observed in 22 patients $(9.2 \%)$. A reoperation was performed in $1.6 \%$ of cases. These different complications included dural tear $(4.6 \%)$, wound infection $(3.3 \%)$, stroke $(0.8 \%)$, cauda equina syndrome $(0.4 \%)$ and pseudomeningocele $(0.4 \%)$. The mortality rate was $0.8 \%(n=2)$.

Conclusion: Lumbar canal stenosis surgery is not without complications. Careful selection of patients, consideration of risk factors, and selection of an appropriate surgical strategy can reduce or avoid these complications.

\section{* Corresponding Author:}

Holden Olatoundji Fatigba, MD.

Address: Department of Neurosurgery, Medicine School of Parakou University, Borgou, Benin, Africa

Tel: +22 (99) 7492245

E-mail: holfatigba@gmail.com 


\section{Highlights}

- Two hundred thirty-nine patients were operated for LSS.

- Twenty-two cases (9.2\%) had different complications including infections, stroke, cauda equina syndrome, and dural tear.

- To reduce or avoid the complications, patients should be selected with enough care and all potential risk factors along with an appropriate surgical strategy should be considered.

\section{Plain Language Summary}

Management of Lumbar Spinal Stenosis (LSS) is common in neurosurgery. The authors of this study report the results and complications observed during 8 years. A retrospective, descriptive, and cross-sectional study was conducted from January 2010 to December 2018 at a teaching hospital in Benin (West Africa). This study included patients who had undergone surgery for lumbar canal stenosis. During the study, 239 patients were selected ( $56.5 \%$ male and $43.5 \%$ female patients). Their mean age was $52.3 \pm 10.9$ years. Results were favorable in $90 \%$ of the cases. The results were excellent, good, acceptable, or poor. The complication and mortality rates were $9.2 \%$ and $0.8 \%$, respectively. These complications were superficial or wound infections, dural tear, and neurological aggravation (cauda equina syndrome). Two complications were exceptional: stroke and pseudomeningocele. These different complications were managed. Lumbar canal stenosis surgery is not without complications. This rate is, however, low with sometimes exceptional complications

\section{Introduction}

umbar Spinal Stenosis (LSS) is one of the most common degenerative spinal disorders. Both the clinical manifestations and imaging facilitate the diagnosis and selection of surgical strategy [1-4]. Surgical management of LSS is very important in neurosurgical practice in sub-Saharan Africa [5-9]. Based on the published literature, the post-operative results are usually satisfactory. Although the related complications are not rare, some of them are frequently described [10-15]. However, other complications are exceptional and particularly serious $[16,17]$. Whatever the type of associated complications with degenerative spine surgery, it is now possible to reduce the frequency and severity of these complications and to prevent them [18-21]. The present study was conducted to complete a series of works devoted to the degenerative spine in our department $[6,22]$. The objective of this study was to report the morbidities and mortalities observed during surgical treatment of LSS and the outcome of these patients after management over an 8-year study period.

\section{Methods and Materials/Patients}

This was a retrospective, descriptive and transversal study performed from January 2010 to December 2018 at the neurosurgery unit of the Departmental Teaching Hospital of Borgou-Alibori in Benin. This study concerned patients who underwent surgical management for LSS The diagnosis of LSS was established by clinical and imag ing data (lumbar CT scan, myelography, or MRI). Based on the operating procedure and hospitalization records of these patients, all reported complications were recorded. These were pre-operative or post-operative complications. All patients diagnosed with LSS and undergoing surgical management were included. Criteria for the postoperative functional outcome of patients [6] are reported in Table 1. Among these patients, all cases whose outcomes could not be evaluated or documented during the post-operative period were excluded. We considered all complications that occurred between the 1 st and the $30^{\text {th }}$ day after surgery a post-operative complication. All types of complications, their management, and the patient's outcome were reported. The variables studied were age, gender, type of complication and its occurrence, the performed treatment, the patient's outcome, and mortality.

\section{Results}

During the study period, 270 patients underwent laminectomy for lumbar canal stenosis. Among these patients, 239 were selected for the assessment of complications and mortality. These patients were divided into 135 men (56.5\%) and 104 women (43.5\%). The mean age of the 
Table 1. Criteria for the evaluation of functional outcomes in patients operated for LSS

\begin{tabular}{|c|c|c|c|c|}
\hline Items & Excellent & Good & Acceptable & Poor \\
\hline Symptoms & Full regression & Good regression & Partial regression & No regression \\
\hline Motors signs & Full recovery & Good recovery & Partial recovery & No improvement or aggravation \\
\hline $\begin{array}{c}\text { Taking medication after } \\
\text { surgery }\end{array}$ & Ceased & Sporadic & Frequent & Permanent \\
\hline $\begin{array}{l}\text { Functional physio- } \\
\text { therapy }\end{array}$ & None & Brief & $\begin{array}{l}\text { Partial dependency } \\
\text { or changed work } \\
\text { position* }\end{array}$ & Permanent \\
\hline Complete recovery & 3 months & 3-6 months & Continuous & $\begin{array}{l}\text { Dependence or inability to } \\
\text { return to work }\end{array}$ \\
\hline Improvement time & $\leq 3$ months & 3-6 months & 6-9 months & $\begin{array}{l}\text { No improvement over } 9 \\
\text { months }\end{array}$ \\
\hline
\end{tabular}

patients was $52.3 \pm 10.9$ years. Their mean weight and mean height were respectively $75 \pm 14.4 \mathrm{~kg}$ and $171 \pm 9.2$ $\mathrm{cm}$. Laminectomy was performed on one, two, and three lumbar spinal segments in 42 (17.6\%), 133(55.6\%), and $64(26.8 \%)$ cases, respectively. The detailed distribution of the different spinal segments is reported in Table 2. Laminectomy was associated with discectomy in 15 patients (6.3\%). No arthrodesis with spinal fixation was performed. The mean duration of operation was $95.4 \pm 17.9$ minutes (ranging from 52 to 154 minutes) and the mean hospital stay was $11.4 \pm 3.5$ days (ranging from 2 to 30 days).

Out of 239 patients, 215 (90\%) had no post-operative complications. Five types of complications (Table 2) were observed in 22 patients (9.2\%). Functional post-operative outcomes were considered excellent, good, acceptable, and poor in $32.1 \%, 52.1 \%, 10.9 \%$ and $4.9 \%$ of the cases, respectively. Reoperation was performed in 4 patients because of these complications. The mortality rate was found to be $0.8 \%(n=2)$. These different complications are outlined below:
Wound infection (3.3\%): This involved parietal and deep suppuration with a defect in the healing and disunion of the operative planes (Figure 1A). These suppurations had occurred successively during the same period. Swabbing and pus sampling from the operative wounds revealed Pseudomonas aeruginosa and Eschericha coli in 5 cases (62.5\%). Based on the results of the antibiogram, antibiotherapy was instituted, the outcome was satisfactory and good healing was obtained (Figure 1B). Two patients were re-operated and benefited from deep lavage with a debridement of necrotic tissues. General disinfection of the surgical room was also performed.

Dural tear (4.6\%): These were dural tear that occurred during surgery. Among these cases of dural tear, Cerebrospinal Fluid (CSF) leakage was frankly visible in $2.5 \%$ of cases. These leaks were repaired by direct suture. Postoperative monitoring and outcome were satisfactory.

Pseudomeningocele (0.4\%): This was a 46-year-old patient who underwent L4-L5 laminectomy. He had a history of lumbar discectomy performed two years previously.

Table 2. The distribution of the different lumbar spinal segments where a laminectomy was performed.

\begin{tabular}{|c|c|c|}
\hline Lumbar Spinal Segments & Frequency & Percentage \\
\hline L4 & 34 & 14.2 \\
\hline $\mathrm{L} 5$ & 8 & 3.4 \\
\hline L3-L4 & 12 & 5 \\
\hline L4-L5 & 121 & 50.6 \\
\hline L3-L4-L5 & 64 & 26.8 \\
\hline
\end{tabular}




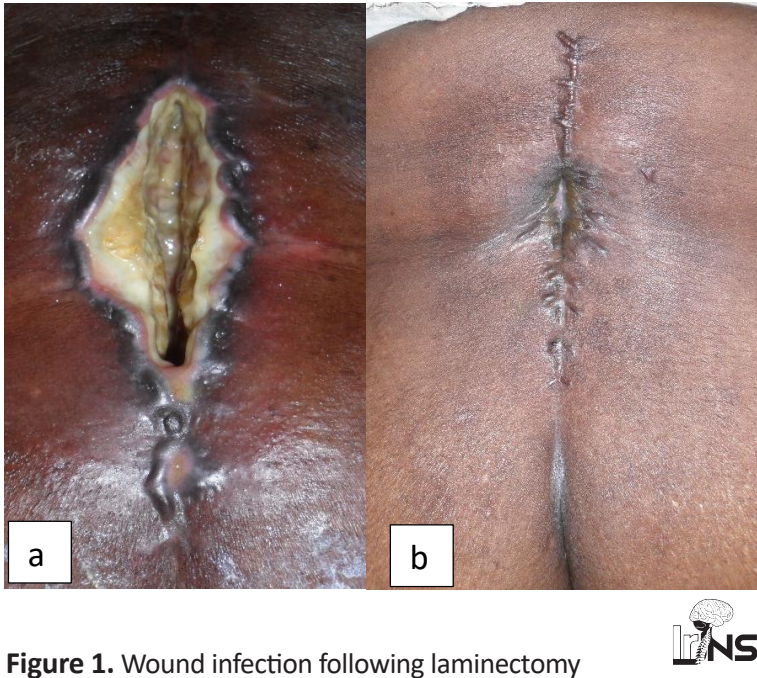

A: Before; and B. After the treatment

The post-operative follow-up was simple. Three weeks after the laminectomy, he was readmitted for lumbar swelling (Figure 2A) over the operative site and persistent headache. The puncture of this tumefaction produces CSF. This tumefaction was reconstituted 24 hours after the procedure. The patient was then re-operated for a macroscopic pre-operative examination. A large dural opening was found (Figure 2B). This tear was closed by dural suture in combination with an aponeurotic patch (Figure 2C). The post-operative follow-up was simple.

Cauda equina syndrome (0.4\%): This was a 46 -year-old patient admitted with a narrowed lumbar canal L4-L5 with bilateral radicular claudication and a perimeter of walking less than $200 \mathrm{~m}$. He had no genito-sphincter disorders. He underwent an L4-L5 laminectomy. When awake, he was discovered to have a cauda equina syndrome, saddle anesthesia and abolition of all osteo-tendinous and cutaneous reflexes in both pelvic limbs. Anal responsiveness was present but there was relaxation of the anal sphincter. The patient was immediately readmitted to the operative room. Intraoperatively, no hematoma or specific lesions were found. The patient was referred for intensive functional rehabilitation. No recovery was observed.

Stroke $(0.8 \%)$ : This was a stroke that occurred when the patients awoke, although no intraoperative incidents were reported during the surgery. The first case involved a 56-year-old patient who was diagnosed with lumbar canal stenosis. Pre-operative examinations and pre-anesthetic consultation revealed no abnormalities or physiological failure. She was classified as grade II on the American Society of Anesthesiologists (ASA) classification [20]. She underwent an L3-L4-L5 laminectomy. The procedure took 105 minutes performed under general anesthesia. Upon waking, an adynamic condition and incomplete right hemiplegia were observed. The brain CT scan was performed with and without the injection of contrast material (Figure 3). No parenchymal abnormalities were observed.

The second patient, 61 years old, underwent an L4L5 laminectomy. On awakening, she had facial paralysis and dysarthria. The cerebral CT scan with and without contrast performed within 24 hours was normal. The diagnosis of post-operative ischemic stroke was retained. Both patients were treated with Low Molecular Weight Heparin (LMWH) and functional rehabilitation. After six weeks, the outcome of treatment was favorable. All of

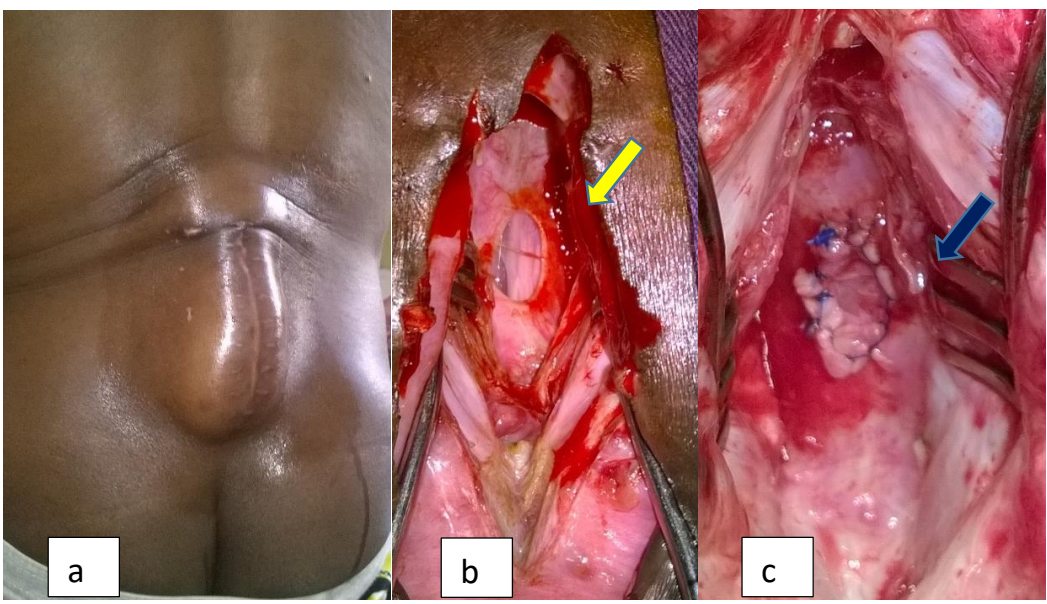

Figure 2. Pseudomeningocele after laminectomy

A: Lumbar swelling over operative site; B. Intraoperative view showing a large dural tear with regular (yellow arrow) contour and precise limit. Leakage of CSF was observed but no root avulsion; C. Surgical repair by dural suture in combination with an aponeurotic patch (Blue arrow) 
Table 3. Distribution of post-operative complications observed among the 239 patients operated for lumbar spinal stenosis

\begin{tabular}{cccc}
\hline Types of Complications & No. (\%) & Treatment & Outcome \\
\hline Wound infection & $8(3.3)$ & Antibiotic/surgical repair & Recovery \\
\hline Dural tear * & $11(4.6)$ & Surgical repair & Recovery \\
\hline CSF leak & $6(2.5)$ & Surgical repair & Recovery \\
\hline Pseudomeningocele & $1(0.4)$ & Surgical repair & Recovery \\
\hline Cauda equina syndrome & $1(0.4)$ & Surgery & No improvement \\
\hline Stroke & $2(0.8)$ & LMWH and functional reduction & Complete recovery \\
\hline * Dural tear with and without CSF leak & & &
\end{tabular}

these post-operative complications and their outcome are summarized in Table 3.

Post-operative death $(\mathbf{0 . 8 \% )}$ : This result is from two cases of cardiac failure with an unknown origin that occurred at the end of the operation. These patients did not seem to be high risk during the pre-anesthetic consultation and both of them underwent operation using general anesthesia.

\section{Discussion}

Lumbar spine surgery for various reasons is common in neurosurgical departments, even in under-equipped

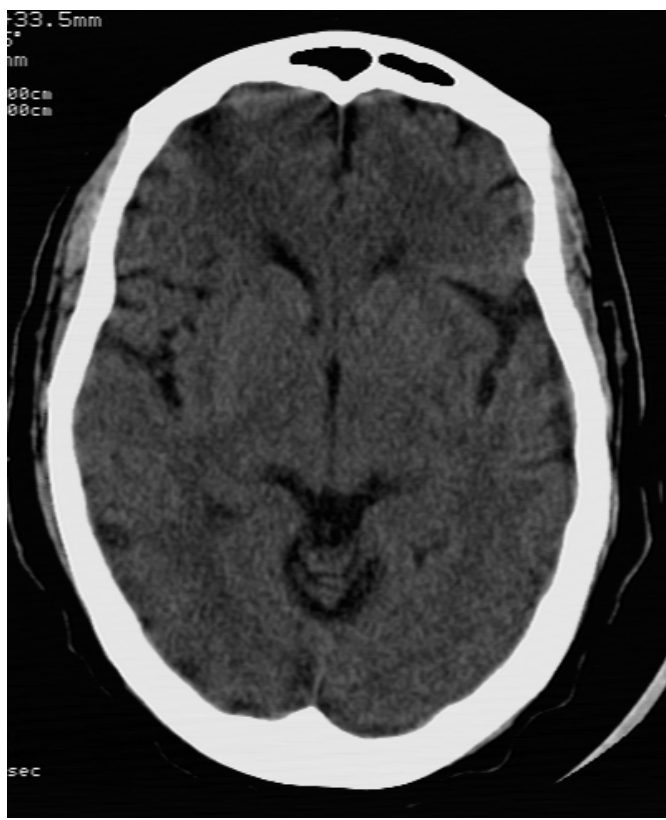

Figure 3. Brain CT scan for the first patient without the injection of contrast material, performed the day after the occurrence of a post-operative stroke. There are no softening lesions or cerebral infarction. medical centers $[5,6,8,9]$. Owing to the high incidence of lumbar spine surgeries, institutional surveillance is necessary to keep the surgical standards at a standard level $[10,17,23]$. This evaluation identifies the causes of morbidity and mortality and thus enables the causes to be identified and corrected. It also contributes to a better pre-operative assessment of the risks, a good selection of patients, and finally a reduction in the mortality and morbidity of this surgery [10, 20, 21, 24, 25]. Like several authors before us $[9,10,14,15]$, by performing this study over a long period and with a large sample size, we are performing a self-assessment of the practice of degenerative spinal surgery in Parakou (Benin). There are two types of post-operative morbidity associated with lumbar canal stenosis: Surgical morbidity and morbidity due to the health condition of the patient him/herself and the problems regarding operating environment $[19,26]$.

The surgical outcome for instrumented as well as noninstrumented lumbar spine surgery, have been reported as favorable in most studies $[3,6,9,17]$. The complication rates are relatively low but remain a concern. We reported a complication rate of $9 \%$ and mortality of $0.8 \%$. These complications can be subdivided into three groups: Usual complications (like surgical site infection-SSI), incidental durotomy (as post-operative pseudomeningocele), and exceptional complications (such as stroke in the current study) $[16,24,27]$. The occurrence of these various complications and the distant residence of patients in relation to the hospital explain the relatively long hospitalization in our study.

The frequency of post-operative complications of LSS varies from study to study. The rate was $7 \%$ according to Fu et al. [10], 7.6\% according to Schoenfield et al. [25], whereas Djientcheu et al. [5] reported a relatively higher rate of $10.9 \%$. In searching for factors predictive of complications, some authors wanted to establish a correlation 
between patient's age, body mass index, ASA score, and spinal surgery history $[10,15,21,25]$. The mean age of our patients was $52.3 \pm 10.9$ years. This age was $55.9 \pm 14.5$ years according to Schoenfield et al. [25], $53.1 \pm 17.5$ years according to Péreira et al. [21], 51.47 years according to Sanoussi et al. [9] and 57.3 years according to Djientcheu et al. [5]. All these authors, like others [4, 15], have not found a correlation between the age of the patients and the occurrence of post-operative complications. However, the risk may increase with age. Dexo et al. [18] reported a complication rate of $18 \%$ in patients over 75 years of age. For other authors [19, 26], these predictive factors have been cited as increasing the risk of complications. Consequently, age over 80 years, ASA classification over 2, and operation duration over 304 minutes would increase the risk of complications.

Wound infection and dural tear are the most reported complications of lumbar canal stenosis surgery. They are the main causes of revision surgery $[12,21,28]$. These infections, whether parietal or deep, have been reported in all studies $[1,11,14,17]$, which may either happen with or without instrumentation. The infection rate was $3 \%$ in our study. This rate is similar to that reported by Djientcheu et al. [5] and Smith [14] which were 3.9\% and $4.9 \%$, respectively, higher than $2.1 \%$ that was reported by Fu et al. [10] and lower than $7.31 \%$ that was reported by Pereira et al. [21]. Instrumental fixation and a long duration of the procedure would expose the patient to an infectious risk. However, this hypothesis is not accepted by all authors. Good preparation of the patient and compliance with pre-operative measures should contribute to a decisive reduction in the rate of infection. When the causative germ can be isolated, it is easier to treat the infection. Dural tear appears to be related to this surgery [1, $5,10,12,28]$ with varying frequencies. Of a rate of $3.1 \%$ reported by Fu et al. [10], they can reach $4.9 \%, 5.8 \%$, or even $7.4 \%$ as reported respectively by Djientcheu et al. [5], Kamemora et al. [12], and Strömqvis et al. [28]. These dural tears are a concern when leakage of CSF follows. They may be evident as well as only revealed by an influx of CSF into the surgical field. They must be repaired as much as possible. In our study, the tear was repaired by direct suturing. Ignorance of a dural tear or a failure to repair can lead to pseudomeningocele or even more serious complications [28]. Pseudomeningocele after spinal surgery is exceptional but not so rare $[29,30]$. It can occur after an unknown dural breach. However, a history of spinal surgery increases the risk of occurrence. The diagnosis can be made not only through imaging but also with intraoperative exploration. Using a direct suture re- pair combined with an aponeurotic patch with or without biological glue is effective.

Post-operative neurological compromise is a major concern. Although in all studies, the frequency remains low [31], every effort should be made to prevent the occurrence of a complication. When they occur, neurological aggravation is an extreme emergency that requires postoperative imaging [32].

The occurrence of stroke after spinal surgery is rare and undocumented [10, 16, 21, 33]. Spinal surgery is not described as being at risk for such a complication, however, the sequelae of which are serious and may be permanent $[34,35]$. The patients concerned were operated under the same conditions including the type of anesthesia, and even the duration of the operation. Generally, the patients were in good condition and had no risk factors. According to Hogue et al. [36], there are neurological risks associated with the patient or the anesthesia procedure These risks would be a history of stroke, female gender, or diabetes. Both of our patients were female but neither had a medical history of stroke. Anesthetic risks are related to blood pressure fluctuations during the procedure [27]. According to Ecker et al. [37], surgical posture may be responsible for this due to the hemodynamic changes it causes, including spinal disc surgery as reported by Lipton [34]. For Shriver et al. [38], spinal surgery in the genu pectoral position and an operation time of more than 240 minutes would be a risk factor. The hypothesis of a postural hemodynamic disorder could explain the focal deficit observed in these two patients. In order to remedy such serious complications which are causes of death, Lessing et al. [20] propose spinal anesthesia as an alternative for patients aged over 70 years.

The lethality associated with lumbar spinal stenosis surgery is a serious problem. The operative procedure generally does not endanger the patient's health and by no means is regarded as a high-risk procedure $[3,8,17]$. This mortality was $0.1 \%$ according to Fu et al. [10] (with the observation that the patients who died in this study were over 60 years of age), $0.5 \%$ according to Shamji et al. [4] in an elderly population, and $0.3 \%$ according to Schrongield et al. [25]. The evoked causes were cardiac or respiratory failure or thromboembolic complications. Mortality thus seems to be related to the physiological condition of patients at the time of surgery. Therefore, it is advisable to highly consider the indications for surgery and carefully select the patients for operation. It is important to balance the expected benefit of this surgery, the risk incurred and the patient's condition. The surgical benefitrisk assessment then becomes mandatory to reduce or 
even contain the lethality associated with LSS surgery [11, $18,19,23$ ]. An alternative solution could then be provided for high-risk patients while using appropriate surgical and anesthesiological procedures [13, 20].

\section{Conclusion}

Complications can occur after surgery for LSS. Although the rates are relatively low, these complications remain serious. In our study, three groups of complications should be highlighted: the usual complications such as infections and dural tears, exceptional complications such as pseudomeningoceles, and rare complications such as strokes. All of these complications were experienced in patients considered eligible for surgery. Careful selection of patients, consideration of risk factors, and selection of an appropriate surgical strategy can reduce or avoid these complications. However, when a complication occurs, early management offers the best chance of complete recovery.

\section{Ethical Considerations}

\section{Compliance with ethical guidelines}

This research was confirmed by Local Ethical Committee for Biomedical Research of the University of Parakou (CLERB-UP).

\section{Funding}

This research did not receive any grant from funding agencies in the public, commercial, or non-profit sectors.

\section{Authors' contributions}

Conception, design, data collection: Holden Olatoundj Fatigba; Data analysis and interpretation: Luphin Hode; Drafting the article: Luphin Hode, Thierry Alihonou; Data analysis and interpretation: Kisito Quenum; Critically revising the article: Thierry Alihonou, Kofi-Mensa Savi de Tove, Alexandre S. Allodé; Reviewing submitted version of manuscript and approving the final version of the manuscript: All authors.

\section{Conflicts of interest}

The authors have no conflicts of interest.

\section{References}

[1] Haden N, Whitfield P, Moore A. The management of degenerative lumbar Spine disease. Advances in clinical neuroscience \& rehabilitation. 2005; 4(6):38-39.

[2] Overdevest GM, Moojen WA, Arts MP, Vleggeert-Lankamp CL, Jacobs WC, Peul WC. Management of lumbar spinal stenosis: A survey among Dutch spine surgeons. Acta Neurochirurgica (Wien). 2014; 156(11):213945. [DOI:10.1007/s00701-014-2186-6] [PMID]

[3] Postacchini F. Management of lumbar spinal stenosis. The Journal of Bone and Joint Surgery. 1996; 78-B (1):154-64. [DOI:10.1302/0301620X.78B1.0780154]

[4] Shamji MF, Mroz T, Hsu W, Chutkan N. Management of degenerative lumbar spinal stenosis in the elderly. Neurosurgery. 2015; 77 (Suppl4):S68-74. [DOI:10.1227/NEU.0000000000000943] [PMID]

[5] Djientcheu VDP, Njamnshi AK, Singwe MN, Bello F, Yamgoue YT, Eloundou NJ, et al. [Spinal canal stenosis: About 102 cases at the Yaoundé Central Hospital (French)]. Revue Africaine de Chirurgie et Spécialités. 2010 4(8):8-11. [DOI:10.4314/racs.v4i8.67883]

[6] Fatigba OH, Belo M, Pape AG, Savi de Tove K-M, Alihonou T, Lawin EBL and al. [Lumbar canal stenos: Surgical and functional outcome in a neurosurgery ward, Benin (French)]. African Journal of Neurological Sciences. 2015; 34(1):17-25. https://www.researchgate.net/publication/290519442

[7] Kabre A, Ba MC, Cisse R, Sorgho CL, Doli P, Kabore J. [Lumbar canal stenosis in Ouagadougou: Aetiological, clinical aspects and prognosis regarding 80 cases (French)]. Dakar Medical. 2003; 48(2):138-41. [PMID]

[8] Park BE. Surgical treatment of degenerative lumbar spine disease in Sub-Saharan Africa: A retrospective study of 450 cases and its future implications. World Neurosurg. 2015, S1878-8750(15)01690-3. [DOI. org/10.1016/j.wneu.2015.11.077]

[9] Sanoussi S, Bawa M, Maman R, Guemou A, Boureima M. [Management of lumbar spinal canal in Niamey (French)]. Revue Internationale De Médecine De Côte D'ivoire. 1996; 13:197-201.

[10] Fu KMG, Smith JS, Polly Jr DW, Perra JH, Sansur CA, Berven SHand al. Morbidity and mortalily in the surgical treatment of 10,329 adults with degenerative lumbar stenosis. Journal of Neurosurgery. 2010; 12(5):443-6. [DOI:10.3171/2009.11.SPINE09531] [PMID]

[11] Imagama S, Kawakami N, Tsuji T, Ohara T, Matsubara Y, Kanemura Tand, et al. Perioperative complications and adverse events after lumbar spinal surgery: Evaluation of 1012 operations at a single center. Journal of Orthopaedic Science. 2011; 16(5):510-5. [DOI:10.1007/s00776-0110123-6] [PMID]

[12] Kamenova M, Leu S, Mariani L, Schaeren S, Soleman J. Management of incidental dural tear during lumbar spine surgery. To suture or not to suture? World Neurosurg. 2016; 87:455-62. [DOI:10.1016/j. wneu.2015.11.045]

[13] Lee JY, Moon SH, Suh BK, Yang MH, Park MS. Outcome and complications in surgical treatment of lumbar stenosis or spondylolisthesis in geriatric patients. Yonsei Medical Journal. 2015; 56(5):1199-205 [DOI:10.3349/ymj.2015.56.5.1199] [PMID] [PMCID]

[14] Smith JS, Shaffrey Cl, Sansur CA, Berven SH, Fu KM, Broadstone PA, et al. Rates of infection after spine surgery based on 108,419 procedures: A report from the scoliosis research society morbidity and mortality committee. Spine (Phila Pa 1976). 2011; 36(7):556-63. [DOI:10.1097/ BRS.0b013e3181eadd41] [PMID] 
[15] Ulrich NH, Kleinstück F, Woernle CM, Antoniadis A, Winklhofer S Burgstaller JM, et al. Clinical outcome in lumbar decompression surgery for spinal canal stenosis in the aged population: A prospective Swiss multicenter cohort study. Spine (Phila Pa 1976). 2015; 40(6):415-22. [DOI:10.1097/BRS.0000000000000765] [PMID]

[16] Fatigba $\mathrm{OH}$, Houndjé $\mathrm{P}$, Houensou $\mathrm{HI}$, Tchaou AB. [Cerebral stroke: Unusual perioperative complication of a lumbar laminectomy (French)] Annales de l'Université de Parakou Série Sciences de la Santé. 2013, 3(1):32-3.

[17] Katz JN, Lipson SJ, Larson MG, McInnes JM, Fossel AH, Liang MH. The outcome of decompressive laminectomy for degenerative lumbar stenosis. Journal of Bone and Joint Surgery. 1991; 73(6):809-16. [DOI:10.2106/00004623-199173060-00003] [PMID]

[18] Deyo RA, Cherkin DC, Loeser JD, Bigos SJ, Ciol MA. Morbidity and mortality in association with operations on the lumbar spine. The influence of age, diagnosis, and procedure. Journal of Bone and Joint Surgery. 1992; 74(4):536-43. [DOI:10.2106/00004623-199274040-00009] [PMID]

[19] Lee MJ, Hacquebord J, Varshney A, Cizik AM, Bransford RJ, Bellabarba $C$, et al. Risk factors for medical complication after lumbar spine surgery: A multivariate analysis of 767 patients. Spine. 2011; 36(21):1801. [DOI:10.1097/BRS.0b013e318219d28d] [PMID]

[20] Lessing NL, Edwards CC , Brown CH, Ledford EC, Dean CL, Lin C, et al. Spinal anesthesia in elderly patients undergoing lumbar spine surgery. Orthopedics. 2017; 40(2):e317-e22. [DOI:10.3928/0147744720161219-01] [PMID]

[21] Pereira BJ, de Holanda CV, Ribeiro CA, Holanda LF, Cabral CD, Caravalho $\mathrm{LL}$, et al. Spinal surgery for degenerative lumbar spine disease: Predictors of outcome. Clinical Neurology and Neurosurgery. 2016; 140:1-5. [DOI:10.1016/j.clineuro.2015.11.004] [PMID]

[22] Fatigba H, A Hans-Moevi A, Belo M, Savi de Tové KM, G Pape A, Mijiyawa M. Aetiology of the lumbar spinal stenosis in black Africans: Intraoperative observations. Iranian Journal of Neurosurgery. 2015; 1(1):358. [DOI:10.18869/acadpub.irjns.1.1.35]

[23] Aghayev E, Mannion AF, Fekete TF, Janssen S, Goodwin K, Zwahlen $M$, et al. Risk factors for negative global treatment outcomes in lumbar spinal stenosis surgery: A mixed effects model analysis of data from an international spine registry. World Neurosurgery. 2020; 136:e270-83. [DOI:10.1016/j.wneu.2019.12.147]

[24] Bateman BT, Schumacher HC, Wang S, Shaefi S, Berman MF. Perioperative acute ischemic stroke in noncardiac and nonvascular surgeryincidence, risk factors, and outcomes. Anesthesiology: The Journal of the American Society of Anesthesiologists. 2009; 110(2):231-8. [DOI:10.1097/ALN.0b013e318194b5ff] [PMID]

[25] Schoenfeld AJ, Ochoa LM, Bader JO, Belmont PJ Jr. Risk factors for immediate postoperative complications and mortality following spine surgery: A study of 3475 patients from the National Surgical Quality Improvement Program. Journal of Bone and Joint Surgery. 2011; 93(17):1577-82. [DOI:10.2106/JBJS.J.01048] [PMID]

[26] Lurie J, Tomkins-Lane C. Management of lumbar spinal stenosis. The BMJ. 2016; 352:h6234. [DOI:10.1136/bmj.h6234] [PMID] [PMCID]

[27] Bijker JB, Persoon S, Peelen L. Intraoperative hypotension and perioperative ischemic stroke after general surgery. A nested casecontrol study. Anesthesiology. 2012; 116:658-64. [DOI:10.1097/ ALN.0b013e3182472320] [PMID]

[28] Strömqvist F, Jönsson B, Strömqvist B. Dural lesions in decompression for lumbar spinal stenosis: Incidence, risk factors and effect on outcome.
European Spine Journal. 2012; 21(5):825-828. [DOI:10.1007/s00586011-2101-2] [PMID] [PMCID]

[29] Lee KS, Hardy IM. Post laminectomy lumbar pseudomeningocele: report of four cases. Neurosurgery. 1992; 30(1):111-114. [DOI:10.1227/00006123-199201000-00020] [PMID]

[30] Gupta R, Narayan S. Post-operative Pseudomeningocele after Spine Surgery: Rare cause of failed back syndrome. Iranian Journal of Neurosurgery (Iran J Neurosurg). 2016; 2(1):15-8 [DOI:10.18869/acadpub. irjns.2.1.15

[31] Ghobrial GM, Williams KA JR, Arnold P, Fehlings M, Harrop JS. latrogenic neurologic deficit after lumbar spinesurgery: A review. Clinical Neurology and Neurosurgery. 2015; 139:76-80. [DOI:10.1016/j.clineutI ro.2015.08.022] [PMID]

[32] Malhotra A, Kalra VB, Wu X, Grant R, Bronen RA, Abbed KM. Imaging of lumbar spinal surgery complications. Insights Imaging. 2015; 6(6):579-90. [DOI:10.1007/s13244-015-0435-8] [PMID] [PMCID]

[33] Limburg M, Wijdicks EF, Li H. Ischemic stroke after surgical procedures: Clinical features, neuroimaging, and risk factors. Neurology. 1998 50:895-901. [DOI:10.1212/WNL.50.4.895] [PMID]

[34] Lipton S. Anaesthesia in the surgery of retropulsed vertebral disc. Anaesthesia. 1950; 5:208-12. [DOI:10.1111/j.1365-2044.1950.
[D. tb12685.x] [PMID]

[35] Selim M. Perioperative stroke. The New England Journal of Medicine. 2007; 356:706-13. [DOI:10.1056/NEJMra062668] [PMID]

[36] Hogue Jr CW, Murphy SF, Schechtman KB, Dávila-Román VG. Risk factors for early or delayed stroke after cardiac surgery. Circulation. 1999; 100(6):642-7.[DOI:10.1161/01.CIR.100.6.642] [PMID]

[37] Ecker A. Kneeling position for operations on the lumbar spine especially for protruded intervertebral disc. Surgery 1949; 25(1):112. [DOI:10.1097/00000542-194911000-00027] [PMID]

[38] Shriver MF, Zeer V, Alentado VJ, Mroz TE, Benzel EC, Steinmetz MP. Lumbar spinesurgery positioning complications: A systematic review. Neurosurgical Focus. 2015; 39(4):E16. [DOI:10.3171/2015.7.FOCUS15268] [PMID] 